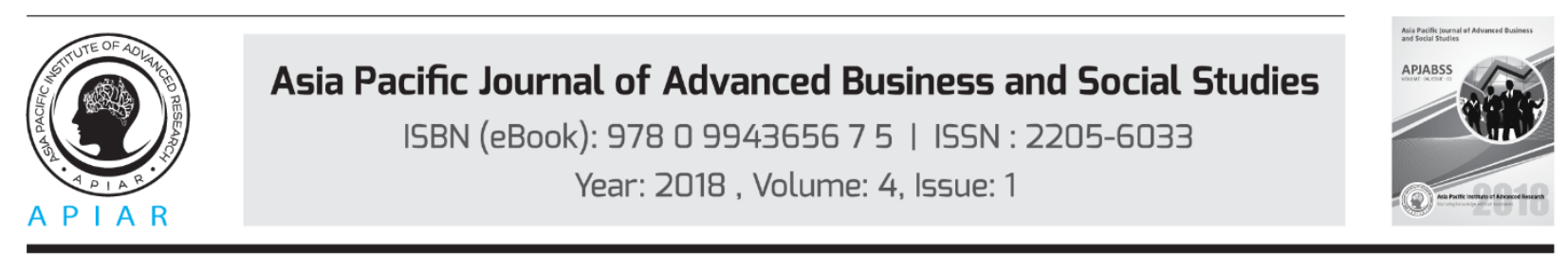

\title{
LANGUAGE MAINTENANCE FACTORS: REFLECTIONS ON THE ARABIC LANGAUGE
}

\author{
Dr. Mostefa Abdelhadi \\ University of Southern Queensland, Australia \\ Email: mostefaabdelhadi@yahoo.com.au
}

\begin{abstract}
The maintenance of community languages has always been a challenging field for investigation. Most of these languages live under the cultural power of the host country language. Therefore, it has never been an easy task for immigrants and their children to maintain their community languages, especially under the linguistic and cultural pressures of the English language. The majority of community languages lose ground to English and adopt it in several domains in everyday life and this is a sign of language shift. This latter is most likely predictable in Englishspeaking countries such as Australia, New Zealand, England and the USA, where English is a dominant and the more prestigious language. In Australia, statistics from a 2016 census demonstrate that only a few languages have withstood the cultural strength and high status of English language (ABS, 2016). As a result of that, the maintenance of community languages remains a major concern for linguists, educators, language activists and for immigrant families, who need to support and maintain these languages for the next generation.
\end{abstract}

Keywords: Language Maintenance, Community Language, Language Shift.

\section{Introduction}

Language maintenance is concerned with the retention of the minority language by its speakers when it is in a constant contact with the majority language. Language maintenance is defined by Baker (2011) as: "relative language stability in the number and distribution of its speakers, its proficient usage by children and adults, and its retention in specific domains (e.g., home, school, religion)" (p. 72). According to Benrabah (2004), language maintenance is the continuous use of the mother tongue, regardless of the cultural pressures from a more prestigious or politically more dominant language. Language maintenance is needed to face the threat of a language shift.

Most of the studies on community languages in Australia have attempted to identify multiple factors that are either conducive or affective to language maintenance (Pauwels, 2005). These factors are diverse and include political, social, demographic, economic, cultural, linguistic, psychological and institutional support factors. The maintenance of the Arabic language can be affected either positively or negatively by these factors.

\section{Language Domain Factors}

Community languages can be maintained through several domains based on the speakers' choices and preferences. These language domains include home/family, friends, neighbours, community, religion, education, and the media, as suggested by Fishman $(1964,1991)$. Baker (2011) points out that the regular use of community languages amongst family, friends, 
neighbours and the local community is referred to as language targets. The use of community languages in the home domain is recorded every five years by the Australian Census (ABS, 2016). However, some of these languages have been maintained in several domains other than the home.

The language maintenance domains were found to be very significant, not just for the maintenance and activation of community languages, but also to reverse these languages in case of any unexpected shift. As argued by Holmes (2013), the minority language is more likely to be maintained and preserved by its speakers if it used in multiple domains.

Kittaneh (2009) conducted research on the language situation of Palestinian Arabs living in Israel. She found that both Arabic and Hebrew were used by the second generation Palestinian Arabs of Israel in their everyday interactions. The results indicated that both languages were well-maintained by the Palestinian Arabic speakers of Israel. The Arabic language was widely used in many domains such as at home with family members, in religious places such as the mosque, in the neighbourhood, the school, and the media. The Hebrew language was used mainly in workplaces and in business.

Likewise, Dweik and Qawar (2015) examined language choice and attitudes among Arab Canadians in Quebec. They reported that the Arabic language was used mostly by Arabic speakers in Quebec in different domains. These domains included the home with their children, the mosque for worship, and in the Arab media such as radio. At the same time, Arabic speakers also used English and French in other domains such as in official spheres and educational institutions. The researchers also concluded that Arabic speakers of Quebec mixed Arabic with French and English in other areas such as in the neighbourhood, with friends, and in their media use.

Based on what has been said in regards to language domains, it is concluded that the dynamic use of the minority language in multiple domains is a sign that the language maintenance is inevitable. Conversely, the limited use of the minority language in private domains such as the home is an indicator of the shift to the majority language (Holmes, 2013; Lee, 2013).

\section{Socio-Demographic Factors}

\subsection{Geographical Concentration}

Research has shown that the geographical concentration of community languages in a particular area can be very helpful for language maintenance (Fishman, 1991; Clyne 2005; Holmes, 2013; Lee, 2013; Sanchez-Castro \& Gil, 2009). Fishman (1991) argued that community languages were better well-maintained by minority groups who were more concentrated within certain geographical areas than those that were more dispersed. Mesthrie, Swann, Deumert and Leap (2009) pointed out that, "the smaller the size of a community, the stronger the threat of language shift and death" (p. 250).

Lee (2013) contended that the geographical concentration of the community in one area allows for the increase of daily interaction and use of the community language outside of the private domain, unlike the dispersed community where the community language was associated with the home domain only. Similarly, Holmes (2013) found that Chinese, who were living in Chinatowns in the US, were more likely to maintain the Chinese language than those who had left the China-town areas.

Additionally, Sanchez-Castro and Gil (2009) investigated the use of the Spanish language among the Salvadorian Community in Queensland and the Spanish Community in South Australia. The results indicated that the former community was successful in maintaining the 
Spanish language in comparison to the latter. The reason was related to the strength in numbers and also the Salvadorians maintained daily contact within their community and other Spanish communities surrounding them.

Arabic language is one of the most concentrated languages in Australia, especially in urban centres, with $69 \%$ of the Arabic-speaking population living in Sydney, 22\% in Melbourne and 9\% living outside these two capital cities (Clyne \& Kipp, 1999). However, the Arabic-speaking community in Toowoomba is not as established as the Arabic speakers who live in the urban settings. The geographical concentration helped in creating social networks, as did institutions such as schools and mosques within the community (Harte, 2010).

In contrast, Arfi (2008) conducted comparative research between Algerian languages in the United States and France. She reported that the concentration of immigrants with the same language was not always an indicator for the maintenance of the community language. Arfi provided some reasons that impeded the transmission of the community language. The first reason was that the majority of educated Algerians in France used the French language in their daily communication even before they emigrated. The second reason related to the generational gap between the first and second generation that prevented language transmission. The third reason was the exposure of children to the French language as the medium of education at school.

\subsection{Length of Stay Since Arrival}

The length of stay since arrival was also found to be an important factor in language maintenance and transmission (Clyne, 2005; Hatoss, 2005; Sanchez-Castro \& Gil, 2009). Clyne (2005) found that recently arrived communities from outside Europe, such as those who came from the horn of Africa and South-East Asia were successful in maintaining their community languages. Similarly, Hatoss (2005) reported that the Hungarian language was more used and preserved at home by the recently arrived Hungarian migrants than the earlier arrival, older generation groups. Turjoman (2013) investigated the role of Arab American mothers in maintaining their Arabic language in Chicago. She found that Arabic was best maintained by mothers who had recently immigrated to America in comparison to earlier arrival Arab Americans. According to the author, the newly arrived mothers were keener to teach their children Arabic than the earlier arrival Arab immigrant mothers.

Likewise, Sanchez-Castro and Gil (2009) investigated the maintenance of the Spanish language of Salvadorian and Spanish groups. They stated that the recently arrived Salvadorians in Queensland tended to maintain their languages more than established Spanish groups in Adelaide.

\subsection{Geographical Proximity}

The geographical proximity and ease of travel to the homeland can be an advantage for language maintenance. Jamai (2008) stated that Moroccan speakers of Arabic, who live in Western Europe, were able to maintain ties with their homeland through mutual visits and marriage, due to the geographical proximity between Morocco and Europe. By contrast, Arfi (2008) argued that proximity to the home country did not necessarily lead to the maintenance of Arabic language among Algerian immigrants who live in France. She found that many Algerians in France adopted the French language in their daily interactions with their children at the expense of their community languages.

Therefore, geographical proximity is not relevant for this study since Australia is very far from the Arabic-speaking countries of the Middle East and North Africa. Arabic is one of the commonly spoken languages of Australia regardless of the geographical distance from the Arabic-speaking countries. 


\subsection{Exogamy and Endogamy}

Research on immigrant languages confirmed that the minority group's marriage patterns could influence the maintenance of the community languages (Baker, 2011; Clyne \& Kipp 1999; Clyne, 2005; Holmes, 2013; Namei, 2012). This influence on community languages could be either negative, through exogamous marriage, or positive through endogamous marriage. Holmes (2013) points out that, "Marriage to a majority group member is the quickest way of ensuring the shift to the majority group language for the children" (p.65). According to Namei (2012), exogamy, or inter-ethnic marriages, contributes to the loss of the community languages, a process during which the language with the higher status and prestige becomes the preferred language for daily communication.

Baker (2011) contended that in a bilingual society, the marriage between a bilingual person from the minority and a monolingual person from the majority language would culminate in monolingual children who spoke the majority language. Census data, collected every five years in Australia, demonstrate in the 2016 census that the shift towards English was very high among the second generation children in Anglo-ethnic marriages (ABS, 2016). For example, second generation children from Malta, Germany and The Netherlands were no longer maintaining their parents' language, and they shifted to English only, whereas Greek and Italian children did maintain their languages to some extent (Namei, 2012). In this respect, Holmes (2013) noted that Greek and Chinese immigrants were not in favour of exogamy, which can be seen as part of maintaining their community languages and to resist language shift.

\section{Cultural Factors}

\subsection{Ethnic Identity}

The maintenance of community languages for many sociolinguistic scholars has a significant relationship with the maintenance and retention of one's identity (Clyne, 1991, Fishman, 1989, 1991, 2000; Hatoss, 2003; Smolicz, 1999). As pointed out by Fishman (1989), the minority language is an important tool for expressing cultural heritage and ethnic identity. Similarly, Cavallaro (2005) noted that language is the key factor representing ethnic identity in multilingual and multicultural contexts. Therefore, it seems that there is a strong connection between language and identity. This firm connection has been considered by Fishman (1991) who contended that "the destruction of a language is the destruction of a rooted identity" (p. 4). According to Fishman, the loss of the language may also lead to a loss of identity.

Albirini (2016) points out the close connection between the Arabic language and identity, in which the vitality of Arabic contributes to the dynamism and maintenance of the ethnic and religious identities. He further explored in his study the participants' multiple identities in regards to the different varieties of Arabic. His results indicated that the majority of the participants, namely the Egyptians, Jordanians, Moroccans and Saudi considered Standard Arabic as a marker for their religious identity as Arab Muslims.

Gogonas (2012) studied second-generation Arabic speakers in Athens, mainly adolescents of the Coptic religion and Muslims. He found that Egyptian Muslim parents were more likely to maintain the Arabic language and transmit it to their children than the Egyptian Copts. However, in this significant study both the Egyptian Muslims and Copts viewed the Arabic language as a core value of their identity due to their daily religious practices. In this respect, Arabic is a symbol of religious identity because it is an authentic language of the Qur'an (Clyne, 2003; Benrabah, 2004). 


\subsection{Family Role}

Research has shown that maintenance of the community language is based on the role of the family at home (Letsholo, 2009; Pauwels, 2005; Velázquez, 2012). The home is the only domain where the family has close control of the children in terms of communication and transmission of the community language. Children are exposed to the majority language of the host country outside the home domain in places such as schools and playgrounds. As indicated by Clyne (2003, 2005), language is not going to survive another generation unless it is transmitted in the home, within the family.

Pauwels's (2005) research about language dynamics in families reported that children who were exposed to a community language at home, usually became more proficient in maintaining good receptive skills even if their productive skills were imperfect. According to the 2016 Census, 16.8\% of the Australian population used a language other than English at home (ABS, 2016). The Arabic language was among the most commonly spoken languages other than English at home in Australia for the period of 1976 to 2016 (ABS, 2016).

The family environment is a motivating factor in the promotion of successful intergenerational maintenance of the community language. However, the language used at home may be affected by external factors such as mixed marriages, the birth of new children, entering the workforce, and children's departure from the parental home (Clyne 2003).

\section{Linguistic Factors}

\subsection{The status of Arabic}

Arabic is the common native language for more than 300 million speakers in the world (Bale, 2010). Most of these speakers live in the Arabic-speaking countries of the Middle East and North Africa (Bale, 2010; Suleiman, 2003). Arabic is among the seven most widely spoken languages in the world (Baker, 2011). Nowadays, the Arabic language is growing quickly with a high number of speakers in the USA, and it is among the six most recognized spoken languages of the United Nations (Temples, 2013). This international status of the Arabic language makes it highly valued by its speakers and encourages them to maintain it for the next generations. As Holmes (2013) argued "the status of a language internationally can contribute to these positive attitudes" (p. 63). However, Clyne (2005) contended that the status of a language internationally does not always culminate in the maintenance of this language. He further claimed that the most widely spoken and prestigious languages in the world, such as German and French, are not well-maintained in Australia. In contrast, languages with less international status, such as Greek and Turkish are well maintained by their speakers (Clyne, 2003, 2005).

Furthermore, the status of Arabic is linked with its prestige as being the language of the Qur'an and Islamic teaching (Benrabah, 2004; Jamai, 2008; Suleiman, 2003). Clyne (2005) pointed to "the symbolic status of Arabic within Islam as the language through which Allah spoke to the Prophet Mohammed and through the Qur'an to His people" (p. 82). In the same context, Rouchdy (2013) refers to the religious status of Arabic as the unique language that is used by all Muslims when they are performing their daily prayers. According to Rouchdy, this religious status of Arabic also represents the religious identity of all Muslims. Hayati and Mashhadi (2010) point out that the Arabic language is taught in Iran alongside the Persian language as the main foreign language to preserve Islamic traditions.

Similarly, Dweik, Nofal and Qawasmeh (2014), in their investigation of Muslim Arabs in Vancouver, found that all the participants demonstrated positive attitudes towards the Arabic language because of its status. The finding revealed that Arabic was considered the most prestigious language among all the participants because of its connection with the Holy Qur'an. 


\subsection{Standardisation of Arabic}

The Arabic language is characterized by diglossia: the existence of a formal or "high" variety, and the vast array of dialects that constitute "low" varieties. High variety refers to Standard Arabic, and low variety refers to informal colloquial Arabic (Suleiman, 2003). As mentioned earlier in Chapter 1, in regards to the linguistic position of Arabic, there are three varieties of Arabic language: a) Colloquial Arabic, or dialect that is spoken language and draws a sense of belonging (identity) (Benrabah, 2007), b) Classical Arabic, which is associated with religion (Hoffman, 2006), and c) Modern Standard Arabic (MSA) which is used in formal domains such as education, media, government and business interactions (Bale, 2010).

In this study, the focus is on Modern Standard Arabic which is used as a medium of instruction in all Arabic schools in Australia (Clyne, 2005). Standard Arabic is the ideal language for communication, which acts as a unifying force among all speakers of the language in the Arab world (Rouchdy, 2013) as well as for non-Arab Muslims who share and use Arabic with the Arabs (Al-Abed Al-Haq \& Al-Masaeid, 2009).

\subsection{Literacy in Arabic Language}

Arabic is the language of literacy and a medium of instruction in all Arab countries. Literacy in the community language helps children to develop their language proficiency and make them feel confident in using the language. However, literacy by itself does not guarantee the maintenance of the language, which implies the need for other language maintenance factors such as the role of the family and the community. As pointed out by Conklin and Lourie (1983), literacy can only be successful in maintaining and reinforcing the community language if the family continues to play its vital role in the home.

In the Australian context, it is pointed out by Rubino (2010), that there has been an emergence of Islamic schools for Arab and Muslim students to promote their Arabic usage and maintain its stability in the host country. The Arabic language is one of the top ten community languages other than English to be taught in the Australian schools (Clyne, 2005).

\section{Socio-Psychological Factors}

\subsection{Positive Language Attitudes}

Many studies on language maintenance have found that speakers' positive attitudes towards community languages may affect the maintenance of such languages strongly and positively (AlNahar, 2009; Dweik et al., 2014; Dweik \& Al-Obaidi, 2014). Al-Nahar (2009) investigated language maintenance among the Armenians of Jordan. The results indicated that the Armenians had positive attitudes towards the Armenian language as they considered it to be the most beautiful and useful language. Furthermore, the Armenian language was seen as an expressive and sentimental language for expressing the speakers' ideas and feelings, especially when they were angry. The results also showed that the Armenian language reflected their identity as Armenians. Additionally, the suffering and challenges to maintain the Armenian language gave them a sense of pride about their ethnicity, identity and history. Al-Nahar also noted that the Armenian language was strictly used at home and the family members were not allowed to use any other language besides Armenian.

Dweik et al. (2014) found that the Arabic-speaking community of Vancouver had positive attitudes towards learning and speaking the Arabic language. Their findings revealed that the Muslim Arabic speakers believed that their language was the most prestigious language since it is the language of the holy Qur'an. The participants stated that Arabic was the most beautiful national language as well as a marker of an Arabic speaker's identity. The results further revealed that Arabic linked the Arabic speakers with their childhood and it reflected their 
cultural heritage. The authors also noted that Arabic-speaking parents wanted their children to be proficient speakers of Arabic by sending them to Arabic schools to learn the language.

Dweik and Al-Obaidi (2014) studied the language situation among the Chaldo-Assyrians in Baghdad, Iraq. They found that Chaldo-Assyrians used the Syriac language in several domains, especially at home with their families and for religious practices. This community also used the Arabic language in other domains such as media, work places and some public places. They also reported that the Chalso-Assyrians community demonstrated a positive attitude towards Syriac and Arabic, and both languages were used side by side by its speakers.

Khadidja (2013) investigated different attitudes of the Kabyle minority group living in Oran, Algeria. Results indicated that the Kabyle are positive towards the maintenance of their mother tongue in spite of the significant impact of Arabic as the national language. They have a positive attitude towards their Kabyle language because they see it as the most beautiful and the richest language. The results also indicated that the Kabyle minority group demonstrated a strong will and loyalty towards their Kabyle language and Tamazight culture by using their language within the family and in other different social contexts. The author claimed that loyalty to the Kabyle language was the main reason for its maintenance and transmission to the second generation children.

\subsection{Emotional Attachment to the Community Language as a Sense of Identity}

Emotional attachment to the community language reshapes the speakers' identity and contributes to the maintenance of their language (Benrabah, 2004; Conklin \& Lourie, 1983; Hatoss \& Sheely, 2009; Gomaa, 2011). Hatoss and Sheely (2009) investigated the maintenance of Dinka language among the Sudanese community in a regional settlement in the South-East Queensland city of Toowoomba, Australia. They reported that the Sudanese community had a strong attachment to their Dinka language.

In the case of Arabic speakers, their emotional attachment to the Arabic language was derived from their emotional attachment to the Qur'an and Islam (Benrabah, 2004). Gomaa (2011) pointed out that the commitment and emotional attachment of the Egyptian parents in Durham, UK towards Arabic formed part of their identity and contributed to the intergenerational transmission of their language to their second generation children. However, the emotional attachment to the language itself could lead to a fear of losing it, since the language represented the identity, and loss of the language would result in the loss of identity (Stoessel, 2002).

\section{Institutional Support Factors}

The maintenance of community languages can be influenced by the availability or the lack of governmental or non-governmental institutions such as media, religious and educational organisations. The availability of these institutions may contribute to the maintenance of the community language while their absence may lead to a language loss. These institutional support factors are an integral part in most language maintenance theories and models (Baker, 2011; Clyne, 2003, 2005; Fishman, 2000).

\subsection{Media}

The media can be one of the important institutional support factors that are needed for the maintenance and transmission of community languages to second generation children (Baker, 2011; Cormack; 2007; Namei, 2012; Pauwels, 2005). Cormack (2007) refers to the benefits of the media in encouraging community languages to be stronger in the face of the dominant culture. He states that: 
...the media can meld people into a sense of a larger community. ... Media can function as a signifier a community is fully modernized, capable of taking part in contemporary life. ...providing media in a language puts a large amount of language use in the public domain, whether in print, video and audio recordings, or multimedia formats. The media can provide economic support and attractive employment (Cormack, 2007, p. $54,55)$.

Similarly, Baker (2011) also refers to the status of community languages when they are used in the media. He contends that media can affect the status and the prestige of the language either positively by its presence or negatively by its absence. Namei (2012) agrees with Baker, in arguing that the availability of the media in minority languages helps in maintaining their stability in terms of the number of speakers, and that it gives them the status and prestige to be used publicly, rather being restricted to private domains. In this sense, the status of the community languages could be increased and promoted through the presence of the media. For example, Lee (2013) investigated the maintenance of the Spanish language among the Chilean community in New Zealand. She referred to the major role of the media in maintaining the Spanish language. She mentioned that the popularity of television series Dora the Explorer had a strong impact on the status of the Spanish, in the sense that young children were attracted to the language because of popular programs like that.

Similarly, Jamai (2008) investigated language maintenance among the Moroccan community in Britain. He found that $80.1 \%$ of Moroccan immigrants had access to TV channels through satellite cables. The results indicated that Moroccans also used other types of media such as listening to radio in Moroccan Arabic, and reading books and newspapers in Arabic. The results further revealed that English was the dominant language in the printed media and the majority of the Moroccan immigrants preferred reading in English rather than in Arabic. Jamai further found that the majority of the Moroccan community favoured the audio-visual media because it represented their linguistic and cultural heritage through varied programs broadcasted from their home country.

\subsection{Education}

Most importantly, the use of a community language in education contributed to the maintenance and development of a language (Rouchdy, 2013; Rubino, 2010). Rouchdy (2013) studied the Arabic language among the Arab Americans, and she referred to the importance of teaching Arabic as a foreign language in some public schools as well as the increase in enrolments in Arabic classes at universities. Conklin and Lourie (1983) claimed that a low education level restricted social and economic mobility, but they agreed that educated community leaders were loyal to the community language.

In the same context, Gomaa (2011) carried out research on the maintenance and transmission of Egyptian Arabic. He found that a higher educational level of the participants was among the essential factors for maintaining the Arabic language. He claimed that well-educated parents were more likely to be aware of the importance of Arabic for Egyptian and Islamic identity. Usually, well-educated parents had a positive attitude towards the maintenance of their community language.

\subsection{Religion}

Research on language maintenance refers to the major role that religion can play in maintaining immigrant languages (Baker, 2011; Clyne \& Kipp, 1999; Clyne, 2005; Baker, 2011; Fishman 1991, 2000). For example, Baker (2011) points out that: 
The religion can be a strong and important vehicle for the maintenance of a majority and a minority language. The use of classical Arabic in Islam, Hebrew in Judaism, and German among the Protestant Old Order Amish in Pennsylvania illustrates that religion can be a preserver of language (Baker, 2011, p. 57).

Similarly, Fishman (1991) referred to the role of religion in the maintenance of community languages. He reported that classical religious texts such as the Quranic Arabic, Prayer book and Old Testament, had successfully maintained intergenerational language maintenance and transmission.

In the same context, Baker (2011) contended that in Arab and Islamic countries, religion played a significant role in restraining the expansion of English as a prestigious language and preventing it from penetrating a variety of domains.

Clyne and Kipp (1999) did research into the use of Arabic among Australians of Egyptian and Lebanese background in Melbourne. They found that the Arabic language has a strong link to religion within the Muslim community, since the Qur'an was revealed in the Arabic language. Their results also indicated that the Muslim community had been successful in maintaining the Arabic language and transmitting it to their children through teaching and literacy. In their survey data, they confirmed that Arabic is better maintained by the second generation of Muslim Arabic speakers than by the second generation of non-Muslim Arabic speakers. The results indicated that religion is one of the motivating factors in maintaining the Arabic language.

A similar study was conducted by Gomaa (2011) about three Muslim families in Durham, UK. He found that Egyptian Arabic is well-maintained through weekend classes offered to Arab children by the Durham University mosque. The Durham University mosque does not teach children how to read and write in Arabic, but they do learn the verses of the Qur'an through memorization. According to the authors, religion is a driving force for the maintenance of the Arabic language among the Arabic speakers.

In contrast, Di Lucca, Masiero and Pallotti (2008) conducted a study on Moroccan adolescents in Italy. They found that the religion did not play any motivating role in the maintenance of Arabic among Moroccans as they were undergoing a high shift towards the Italian language.

\section{Conclusion}

To sum up, all the language maintenance factors mentioned in this section are seen to be essential for the retention and transmission of the community language when it is in constant contact with the majority language. The availability of some of these factors has a great impact on intergenerational transmission of community languages. These factors seem to work better and in favour of language maintenance when they are combined with each other. For instance, the role of the family at home is crucial for the maintenance of the community language, but needs to be supported by other factors such as the role of the community, literacy using the community language and the media. As mentioned earlier, representation of the community language in the media, availability of religious institutions and the establishment of the schooling system all contribute positively to the maintenance of community languages. Moreover, commitment and positive attitudes of parents can create a proper home environment for learning the language and building cultural and religious identity. 


\section{References}

i. Albirini, A., 2016. Modern Arabic sociolinguistics: Diglossia, variation, codeswitching attitudes and identity.. London and New York: Routledge.

ii. Al-Haq, F. A.-A. \& Al-Masaeid, A., 2009. Islam and language planning in the Arab world: A case study in Jordan. Iranian Journal of Language Studies, 3(3), pp. 267-302.

iii. Almansouri, B., 2014. An investigation of the social and academic experiences of Arabic international students in Australian tertiary education, Queensland: University of Southern Queensland.

iv. Al-Nahar, R., 2009. Language maintenance among the Armenians of Jordan, Amman: The University of Middle East.

v. Arfi, K., 2008. Languages of Algerian diaspora in the United States of America: Comparative study with Algerian diaspora in France, Florida: University of Florida.

vi. Australian Bureau of Statistics, 2016. Census of population and housing, Canberra: s.n.

vii. $\quad$ Baker, C., 2011. Foundations of bilingual education and bilingualism. $5^{\text {th }}$ ed. s.l.:Multilingual Matters.

viii. Bale, J., 2010. Arabic as a heritage language in the United States. International Multilingual Research Journal, 4(2), pp. 125-151.

ix. Benrabah, M., 2004. Language and politics in Algeria. Nationalism and Ethnic Politics, 10(1), pp. 5978.

x. Benrabah, M., 2007. Language-in-education planning in Algeria: Historical development and current issues. Language Policy, Volume 6, pp. 225-252.

xi. Cavallaro, F., 2005. Language maintenance revisited: An Australian perspectives.. The Journal of the national association for bilingual education, 29(3), pp. 561-582.

xii. Clyne, M., 2003. Dynamics of language contact. Cambridge: Cambridge University Press.

xiii. $\quad$ Clyne, M., 2005. Australia's language potential. Sydney: University of New South Wales Press..

xiv. $\quad$ Clyne, M. \& Kipp, S., 1999. Pluricentric languages in an immigrant context: Spanish, Arabic and Chinese. New York: Mouton de Gruyter.

xv. Conklin, N. \& Lourie, M., 1983. A host of tongues: Language communities in the United States. New York: Free Press.

xvi. $\quad$ Cormack, M., 2007. The media and language maintenance. In: M. J. Cormack \& N. Hourigan, eds. Minority language media: Concepts, critiques and case studies. Great Britain: Multilingual matters, pp. 52-68.

xvii. Dweik, B. \& Al-Obaidi, T., 2014. Syriac Language Maintenance among the Assyrians of Iraq.. Journal of Sociology and Social Work, 2(1), pp. 269-282.

xviii. Dweik, B., Nofal, M. \& Qawasmeh, R., 2014. Language use and language attitudes among the Muslim Arabs of Vancouver/ Canada: A sociolinguistic study. International Journal of Linguistics and Communication, 2(2), pp. 75-99.

xix. Dweik, B. \& Qawar, H., 2015. Language choice and language attitudes in a multilingual Arab Canadian community: Quebec- Canada: A sociolinguistic study. British Journal of English Linguistics, 3(1), pp. 1-12.

xx. Fishman, J., 1964. Language maintenance and language shift as a field of inquiry: A definition of the field and suggestions for its further development. Linguistics, 2(8), pp. 32-70. 
xxi. Fishman, J., 1989. Language and ethnicity in minority sociolinguistic perspective, Clevedon: Multilingual Matters.

xxii. Fishman, J., 1991. Reversing language shift: Theoretical and empirical foundations of assistance to threatened languages, Clevedon: Multilingual Matters.

xxiii. Fishman, J., 2000. Language planning for the "other Jewish languages" in Israel: An agenda for the beginning of the 21st century. Language Problems and Language Planning, 24(3), pp. 215-231.

xxiv. Gogonas, N., 2012. Religion as a core value in language maintenance: Arabic speakers in Greece. International Migration, 50(2), pp. 113-129.

xxv. Gomaa, Y., 2011. Language maintenance and transmission: The case of Egyptian Arabic in Durham, UK.. International Journal of English Linguistics, 1(1), pp. 46-53.

xxvi. Harte, E., 2010. Settlement geography of African refugee communities in Southeast Queensland: An analysis of residential distribution and secondary migration, Queensland: Queensland University of Technology, Australia.

xxvii. Hatoss, A., 2003. Identity formation, cross-cultural attitudes and language maintenance in the Hungarian Diaspora of Queensland. Cultural Citizenship Challenges of Globalization, Volume 2, pp. 71-77.

xxviii. Hatoss, A., 2005. Do multicultural policies work? Language maintenance and acculturation in two vintages of Hungarian diaspora in Queensland, Australia. Proceedings of the 4th international symposium on bilingualism, Volume 5, pp. 1001-1009.

xxix. Hatoss, A. \& Sheely, T., 2009. Language maintenance and identity among Sudanese-Australian refugee-background. Journal of Multilingual and Multicultural Development, 30(2), pp. 127-144.

xxx. Hayati, A. \& Mashhadi, A., 2010. Language planning and language-in-education policy in Iran. Language Problems and Language Planning, 34(1), pp. 24-42.

xxxi. Hoffman, K., 2006. Berber language ideologies, maintenance, and contraction: Gendered variation in the Indigenous margins of Morocco. Language and Communication, 26(2), pp. 144-167.

xxxii. Holmes, J., 2013. An introduction to sociolinguistics. 4th ed. New York: Pearson.

xxxiii. Jamai, A., 2008. Language use and maintenance among the Moroccan minority in Britain. [Online]

Available at: http://usir.salford.ac.uk/2030/1/Language Use and Maintenance among the Moroccan Minor ity in Britain-PhD.pdf

xxxiv. $\quad$ Khadidja, A., 2013. Language maintenance and language shift among Kabyle speakers in Arabic speaking communities: The case of Oran, Oran: The University of Oran.

xxxv. Kittaneh, D., 2009. The language situation among the Palestinian Arabs of Israel: A sociolinguistic study.

Available at: http://www.meu.edu.jo/ar/images/data/634344102331718750.pdf

[Online]

xxxvi. Lee, S., 2013. Spanish language maintenance and shift among the Chilean community in Auckland, Auckland: Auckland University of Technology.

xxxvii. Letsholo, R., 2009. Language maintenance or shift? Attitudes of Bakalanga youth towards their mother tongue. International Journal of Bilingual Education and Bilingualism, 12(5), pp. 581-595.

xxxviii. $\quad$ Lucca, L. D., Masiero, G. \& Pallotti, G., 2008. Language socialisation and language shift in the $1 \mathrm{~b}$ generation: A study of Moroccan adolescents in Italy. International Journal of Multilingualism, 5(1), pp. 53-72.

Mesthrie, R., Swann, A., Deumert, A. \& Leap, W., 2009. Introducing sociolinguistics. 2nd ed. Edinburgh, Scotland: Edinburgh University Press. 
xl. Namei, S., 2012. Iranians in Sweden. A study of language maintenance and shift. Sweden: Uppsala University.

xli. Pauwels, A., 2005. Maintaining the community language in Australia: Challenges and roles for families. International Journal of Bilingual Education and Bilingualism, 8(2-3), pp. 124-131.

xlii. Rouchdy, A., 2013. Language conflict and identity: Arabic in the American diaspora'. In: A. Roucchdy, ed. Language contact and language conflict in Arabic: variations on a sociolinguistic theme. New York: Routledge Curzon, pp. 133-148.

xliii. Rubino, A., 2010. Multilingualism in Australia: Reflections on current and future research trends. Australian Review of Applied Linguistics, 33(2), pp. 17-21.

xliv. Sanchez-Castro, O. \& Gil, J., 2009. Two perspectives on language maintenance: The Salvadorian community in Queensland and the Spanish community in South Australia.. International Journal of Language Society and Culture, 6(3-5), pp. 36-47.

xlv. Smolicz, J., 1999. Who is an Australian? Identity, core values and the resilience of culture. In: M. S. \&. J. Zajda, ed. J.J. Smoliczon education and culture. Melbourne: James Nickolas Publishers, pp. 1149.

xlvi. Stoessel, S., 2002. Investigating the role of social networks in language maintenance and shift. International journal of sociology of language, Volume 153, pp. 93-131.

xlvii. $\quad$ Suleiman, Y., 2003. The Arabic language and national identity: A study in ideology.. Washington DC: Georgetown University Press.

xlviii. Temples, A., 2013. Constructing Arabic as heritage: Investment in language, literacy, and identity among young U.S. learners. [Online] Available at: $\underline{\text { http://scholarworks.gsu.edu/cgi/viewcontent.cgi?article=1025\&context=alesl diss }}$

xlix. Turjoman, M., 2013. The Arabic language and the role of mothers in maintaining it among Arab family immigrants in Chicago.. International Journal of Arts and Sciences, 6(3), pp. 659-667.

l. Velázquez, I., 2012. Mother's social network and family language maintenance. Journal of Multilingual Development, pp. 1-14. 